\title{
Is craft beer consumption genderless? Exploratory evidence from Italy and Germany
}

Is craft beer consumption genderless?

\author{
Sergio Rivaroli \\ Department of Agricultural and Food Sciences, \\ University of Bologna, Bologna, Italy \\ Jörg Lindenmeier \\ University of Freiburg, Freiburg, Germany, and \\ Roberta Spadoni \\ Department of Agricultural and Food Sciences, \\ University of Bologna, Bologna, Italy
}

\begin{abstract}
Purpose - This study aimed to investigate the gendered nature of craft beer (CB) consumption in Italy and Germany.

Design/methodology/approach - Data were collected through online surveys in Italy $(N=210)$ and Germany $(N=211)$. Based on an enhanced version of the theory of planned behaviour, mean value difference tests and moderated regression analyses with gender as a moderator were performed to test gender effects on $\mathrm{CB}$ consumption behaviour.

Findings - The study results provide evidence that the gap in $\mathrm{CB}$ consumption behaviour is not very pronounced. In the German sample, gender did not moderate the effects of the model components on behavioural intent. However, the study found significant mean differences in all model variables. In the Italian sample, gender moderated the effects of several components of the theory of planned behaviour on behavioural intention. Hence, $\mathrm{CB}$ consumption appears to represent an opportunity for Italian women to negotiate their womanhood in a historically masculine-dominated space.

Research limitations/implications - The limitations of these data are the focus on two specific countries, the use of small-sized samples and the prediction of behavioural intentions instead of actual behaviour.

Practical implications - The study may help marketing managers develop appropriate marketing strategies based on a better understanding of gender-specific needs in CB consumption.

Originality/value - This investigation provides the first comparative analysis of gender-specific behavioural patterns in $\mathrm{CB}$ consumption in two European countries characterised by notably different beer cultures.
\end{abstract}

Keywords Craft beer, Gender, Consumer behaviour, Theory of planned behaviour, Germany, Italy

Paper type Research paper

\section{Introduction}

There is a widespread belief that there are gender differences in the consumption of alcohol (Beardsworth et al., 2002). Despite there being no reason to doubt the validity of this statement, a clear understanding of the gender differences in beverage consumption is of paramount relevance. Much of the research on alcohol consumption has focused on the role of gender in craft beer (referred to here as $\mathrm{CB}$ ) purchasing and consumption behaviour (Clarke, 2012; Snider, 2016; Darwin, 2017, 2018; Donadini and Porretta, 2017; Gómez-Corona et al., 2016b; Gómez-Corona et al., 2017a, 2017b; Muggah and McSweeney, 2017). This rising

(C) Sergio Rivaroli, Jörg Lindenmeier and Roberta Spadoni. Published by Emerald Publishing Limited. This article is published under the Creative Commons Attribution (CC BY 4.0) licence. Anyone may reproduce, distribute, translate and create derivative works of this article (for both commercial and non-commercial purposes), subject to full attribution to the original publication and authors. The full terms of this licence may be seen at http://creativecommons.org/licences/by/4.0/legalcode

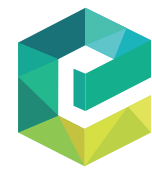

British Food Journal Vol. 122 No. 3, 2020 pp. $929-943$ Emerald Publishing Limited 0007-070X 
$\mathrm{BFJ}$

122,3

930

interest in uncovering the effect of gender on $\mathrm{CB}$ consumption seems to stem from three primary motivations. First, the stagnation of beer consumption has led large brewing companies to look at the sale of $\mathrm{CB}$ as an opportunity to improve their profit margins (Garavaglia and Swinnen, 2018). Second, despite men being heavier beer drinkers than women, approximately 50 per cent of the world's population is represented by females (The World Bank, 2017); this means that brewers can look at this part of the population as a major market opportunity. Finally, and most important for the present study, the commonly assumed reconfigured role of gender in beer consumption allows for hypothesising new consumption patterns that cross gender borders.

From an overview of the literature on the effect of gender on $\mathrm{CB}$ consumption, we can note that cross-national studies on the gendered nature of $\mathrm{CB}$ consumption are still missing. Among European countries, Germany and Italy represent two countries characterised by different beer cultures. Italy does not enjoy a long beer tradition; however, despite Italians being 'light drinkers' of beer, several studies have reported their rising interest in $\mathrm{CB}$ (Aquilani et al., 2015; Donadini and Porretta, 2017; Rivaroli et al., 2018). On the other hand, Germany has a long-standing tradition in beer production and consumption, and Germans are known for being 'heavy beer drinkers'; however, almost 68 per cent of them are not inclined to drink CB (Statista GmbH, 2017). Accordingly, it makes sense to carry out comparative $\mathrm{CB}$ studies in countries with different beer cultures to increase the external validity of $\mathrm{CB}$ research; this rationale also holds for studies that assess gender effects.

\section{Theoretical framework}

In accordance with popular belief, the behaviour of men and women differs in different behavioural domains. Many researchers have explored this idea, and accordingly, it is not surprising that numerous studies have found gender differences in the consumption of food and beverages (Graham et al., 1998; Baraona et al., 2001; Liebman et al., 2003; Roberts, 2004; Kerr et al., 2004; Holmila and Raitasalo, 2005; Lieber, 2006; Mead, 2009; Wilsnack et al., 2009; Clarke, 2012; Snider, 2016; Chapman et al., 2018). Previous research considered gender differences that are caused by the biological sex. In this context, for example, the survey article by Holmila and Raitasalo (2005) highlights that the same amount of alcohol results in different alcohol blood levels among male and female consumers. This difference is due to the fact that the female body contains more lipids and less water. In addition, and among other factors, differences in metabolic processes may also explain that alcohol has a different effect on females. The present study does not explicitly focus on these biological explanatory factors of gender differences in alcohol consumption; rather, socialisation-related and cultural differences in alcohol consumption are considered. Due to the exploratory nature of our study, biological differences are not completely neglected (e.g., genetic explanatory factors).

Meyers-Levy and Loken (2015), in an insightful review article, show three complementary theories that help explain the gender differences in consumer behaviour. The first theory notes that differences in the levels of oestrogen and testosterone influence the brain activities of men and women differently. This theory helps explain differences in the expression of aggression, cognitive skills and the sensation of emotions, among others. The anthropological evolutionary theory represents a second approach that stems from biology, according to Meyers-Levy and Loken (2015). This theory claims that there are several programmes stored in human brains for problem-solving in different situations. In the process of evolution, specific programmes have prevailed, and because our male and female ancestors faced different tasks, it is believed that gender differences exist in these programmes stored in human brains. Gender differences are explained, in particular, by taking into account the problem of finding a partner (i.e., the mating problem). As a consequence of the rivalry for sex partners, it is believed that these evolutionary differences make men behave more aggressively and explain why men are more likely willing to take risks than women. Authors such as Fernie et al. (2010) or 
Gorka et al. (2015) show that a high risk propensity is related to positive attitudes towards alcohol and excessive alcohol consumption; therefore, one can assume that males positively assess CB. Furthermore, in accordance with this theory, men engage more often than women in pretentious and showy consumption behaviour to attract short-term mates (Meyers-Levy and Loken, 2015). Because CB consumption can be seen as hip and cool behaviour, one can assume that men in public places tend to buy products in this beverage category. The third explanatory approach named by Meyers-Levy and Loken (2015) is the sociocultural theory, which assumes, on the one hand, that gender differences in behaviour are due to physical differences and, on the other hand, that they are due to sociocultural influences. Within the scope of the sociocultural approach, gender socialisation theory assumes that gender roles and gender identity result from socialisation. According to Weeks et al. (1999) or Slentz and Krogh (2017), for instance, and based on Freud's (1925) research, early childhood development is assumed to be fundamentally different between boys and girls. More precisely, gender identity is built up to in preadolescence, the age of three years through the relationship with the mother (Chodorow, 1978; Cooper et al., 2013; Ruhl et al., 2015), and socialisation theory states that boys and girls experience a fundamentally different relationship with the mother. After the age of three years, these gender roles are further reinforced; for instance, boys and girls play different kinds of games (Roxas and Stoneback, 2004). In further personality development, social expectations affect individual behaviour by rewarding role-conforming behaviour and punishing non-role-conforming behaviour. The resulting socialisation disparities cause males and females to enter their adult lives with different ideas and goals (Betz et al., 1989). In accordance with former research studies (Kurt and Frimer, 2015, or Newman and Trump, 2019), men strive for promotion (i.e., agency orientation), whereas women strive for the successful completion of the tasks typically assigned to them (i.e., household activities and childcare) and for harmonious relationships (i.e., communal orientation). According to MeyersLevy and Loken (2015), individuals are attracted to brands whose brand personality matches their own gender identity. Because advertising and other media, as well as the behaviour of male role models, often link an image of masculinity with beer consumption and drinking is regarded as a masculine behaviour (Medina-mora, 1994; de Visser and McDonnell, 2012; Darwin, 2018; Fugitt and Ham, 2018), it can be assumed that the perceived personality of CB is more firmly in line with a typical male gender identity. Hence, males should be more inclined towards $\mathrm{CB}$ than females because the consumption of $\mathrm{CB}$ helps men satisfy their desire to demonstrate their masculinity.

The approaches presented thus far help to predict gender differences in $\mathrm{CB}$ consumption and to assume that $\mathrm{CB}$ is more prevalent among male consumers. Gender-related differences in the sensory preference for beer and other alcoholic beverages (Mejlholm and Martens (2006) or Mora et al. (2018) for accordant findings) may be a cause for different consumption levels among male and female consumers. However, due to the multitude of CBs available for consumers, there should be CB available that satisfies the female preference (i.e., sweet and fruity flavours); hence, no general distaste among women can be assumed. In addition, there are further lines of thought that may help explain the missing or unclear gender differences in $\mathrm{CB}$ consumption. The aforementioned sociocultural theory, which focuses more on culturebased explanations, predicts varying effects across different cultures. Thus, gender differences in $\mathrm{CB}$ consumption should be lower in countries, such as Sweden or Germany, where gender equality is more pronounced (Meyers-Levy and Loken, 2015).

Furthermore, the structural theory of sex differences highlights the relevance of situational determinants and explains weak gender effects. Betz et al. (1989) and Dawson (1997) showed that women adapt their behaviour in male-dominated working environments to confirm the male gender role. If one assumes that the situations in which $\mathrm{CB}$ is bought or consumed are dominated by male role models (i.e., beer bars, pubs, brewery restaurants or CB conventions), the structural theory would predict that women adapt their behaviour to these situational
Is craft beer consumption genderless? 
$\mathrm{BFJ}$

122,3

932

circumstances and, consequently, prefer $\mathrm{CB}$ to the same extent as their male companions. Finally, multidimensional theories of gender identity do not conceptualise gender as a binary construct (i.e., males and females). Instead, and in line with authors such as Spence (1993) or Menon (2017), gender is assumed to consist of biological gender, psychological gender and individual attitudes towards socialised gender roles. The psychological gender comprises instrumental or agency-oriented (i.e., male gender roles) and expressive or communal (i.e., female gender roles) components. Accordingly, the gender identity of men may also include female role models and vice versa. In line with this notion, $\mathrm{CB}$ consumption represents an opportunity to negotiate female role models in a historically masculine-dominated space.

Moreover, men adapt to female consumption practices in the form of so-called gender journeys, according to Thompson and Holt (2004). An unambiguous classification of individuals into a binary gender scheme is therefore undoubtedly not possible. Following the gender identity theory on this point, the effects of a binary gender variable on individual $\mathrm{CB}$ consumption, for instance, can only be regarded as a proxy for a multifaceted gender identity. In a study on undergraduate students' alcohol consumption, Dempster (2011) reveals an accordant complex process of gender identity construction. Moreover, a negative attitude of women towards stereotypical female gender roles can encourage women to practise allegedly typical male behaviour such as drinking beer. In line with this notion, gender differences in $\mathrm{CB}$ consumption should not be pronounced. Confirming to this rationale, de Visser and McDonnell (2012) reveal nondifferences in actual alcohol consumption even though typical gender stereotypes appeared in their survey study.

\section{Empirical study}

\subsection{Conceptual framework}

This research takes a more in-depth look at the subject than a previous study conducted by Rivaroli et al. (2019). The conceptual framework of the present study is based on the theory of planned behaviour (TPB; Ajzen, 1991) and considers consumer self-identity (Sparks and Shepherd, 1992) and consumer desire for unique consumer products (Lynn and Harris, 1997) as additional psychosocial motivations that affect the individual's intention to consume CB.

\subsection{Participants}

An online survey was conducted in Italy $(N=210)$ and Germany $(N=211)$ between November and December 2017. A market research company provided access to representative online consumer panels and handled the process of recruiting respondents. Quotas ensured that the gender and age distribution of the sample matched the distributions in the basic population. In addition to a similar age distribution, the Italian consumer sample has a similar profile in terms of education level and willingness to pay for 0.4 lt of CB across the two genders, whereas a gender-specific difference occurred in terms of employment situation (Table I). However, this difference is typical for the basic population, with women occupying more parttime jobs than men. The respondents belonging to the German sample have a similar profile in terms of age and education level, whereas gender differences occur in terms of employment situation and willingness to pay for $0.4 \mathrm{lt}$ of $\mathrm{CB}$, with females having a higher willingness to pay for $\mathrm{CB}$ than men. When comparing the willingness to pay, a distinct difference between Italian and German customers appears. The lower willingness to pay for CB in Germany indicates a sceptical attitude towards $\mathrm{CB}$ that might be a result of the long-standing traditional German beer culture. In particular, the German purity law of 1519 ('Reinheitsgebot'), which prohibits additives in beer, could have contributed to this cultural difference.

\subsection{Questionnaire and measures}

The questionnaire was developed in English and was then translated into the Italian and German language by native speakers. In the opening instructions of the survey, a detailed 


\begin{tabular}{|c|c|c|c|c|c|c|c|}
\hline & $\begin{array}{c}\text { Male } \\
(N=100)\end{array}$ & $\begin{array}{l}\text { Italy } \\
\text { Female } \\
(N=100) \\
\end{array}$ & $\begin{array}{c}p \\
\text { value }^{\mathrm{a}}\end{array}$ & $\begin{array}{c}\text { Male } \\
(N=100)\end{array}$ & $\begin{array}{l}\text { Germany } \\
\text { Female } \\
(N=100)\end{array}$ & $\begin{array}{c}p \\
\text { value }^{\mathrm{a}} \\
\end{array}$ & $\begin{array}{l}\text { Is craft beer } \\
\text { consumption } \\
\text { genderless? }\end{array}$ \\
\hline \multicolumn{8}{|l|}{ Age } \\
\hline Mean (SD) & $40.2(11.2)$ & 38.1 (11.3) & 0.188 & $51.4(14.9)$ & 48.6 (13.2) & 0.159 & \multirow{5}{*}{933} \\
\hline Min & 19 & 18 & - & 21 & 20 & - & \\
\hline $\operatorname{Max}$ & 68 & 63 & - & 87 & 72 & - & \\
\hline Education level & - & - & 0.670 & - & - & 0.154 & \\
\hline $\begin{array}{l}\text { With an academic } \\
\text { degree }\end{array}$ & 44 & 47 & - & 49 & 39 & - & \\
\hline $\begin{array}{l}\text { Without academic } \\
\text { degree }\end{array}$ & 56 & 53 & & 51 & 61 & - & \\
\hline Employment situation & - & - & 0.075 & - & - & 0.000 & \\
\hline Full-time & 72 & 57 & - & 56 & 28 & \multirow{2}{*}{$\begin{array}{l}- \\
-\end{array}$} & \\
\hline Part-time & 10 & 18 & - & 10 & 32 & & \\
\hline Other $^{\mathrm{b}}$ & 18 & 25 & - & 34 & 40 & - & \\
\hline $\begin{array}{l}\text { Willingness to pay for } \\
\text { 0.4lt of craft beer }\end{array}$ & - & - & 0.470 & - & - & 0.008 & \\
\hline$<3.00 €$ & 11 & 20 & - & 42 & 61 & - & \\
\hline $3.00 €-4.00 €$ & 32 & 26 & - & 29 & 26 & - & \\
\hline $4.00 €-5.00 €$ & 29 & 27 & - & 19 & 11 & \multirow{2}{*}{ - } & \\
\hline $5.00 €-6.00 €$ & 18 & 19 & - & 8 & 0 & & \\
\hline$>6.00 €$ & 10 & 8 & - & 2 & 2 & - & \\
\hline \multicolumn{7}{|c|}{$\begin{array}{l}\text { Notes: a Significance level of chi-square test for categorical data, or } 2 \text {-sample } t \text { test for continuous data; } \\
\text { b Significance level of chi-square test } \\
\mathrm{SD}=\text { standard deviation. }\end{array}$} & $\begin{array}{r}\text { Table I. } \\
\text { Sample description }\end{array}$ \\
\hline
\end{tabular}

description of the term 'craft beer' was provided to the participants (i.e., 'craft beer is a beer produced by small independent breweries, and it does not follow the pasteurisation and microfiltration processes during the production phase'). The construct measures adopted in this research were based on the existing measures from previous research (Ajzen, 1991; Lynn and Harris, 1997; Sparks and Shepherd, 1992) and were measured using seven-point Likert scales. All measures are listed in the Appendix.

\subsection{Data analysis}

A principal component analysis (PCA) with an oblique factor rotation (oblimin with Kaiser's normalisation) was performed to examine the unidimensionality of each construct. The sampling adequacy of each domain was tested using the Kaiser-Meyer-Olkin (KMO) measure and Bartlett's test of sphericity. The PCA showed an acceptable unidimensional structure for all the constructs. The KMO values ranged from 0.500 to 0.873 for the Italian sample and from 0.500 to 0.880 for the German sample (Table II), with a significant Bartlett's test $(p<0.05)$ for both samples (Hair et al., 1998). The rotated solution provided the component loadings for each construct. Each loading was higher than the commonly used threshold value of 0.500 and significant. In sum, the results of the PCA indicate the convergent and discriminant validity of the measurement scales. The reliability of each construct was tested using Cronbach's $\alpha$ coefficient, and values below the limit of 0.700 were considered unacceptable (Hair et al., 1998). The Cronbach's $\alpha$ values ranged from 0.728 to 0.968 for the Italian sample and from 0.715 to 0.959 for the German sample (Table II). Thus, the internal consistency of measurements was confirmed.

In a further step, an ordinary least squares (OLS) regression analysis was carried out, with the intention to consume $\mathrm{CB}$ (behavioural intention (BI)) as the dependent variable. The regression analysis considered attitude towards $\mathrm{CB}$ (attitudes (ATT)), social pressure 
BFJ

122,3

\section{4}

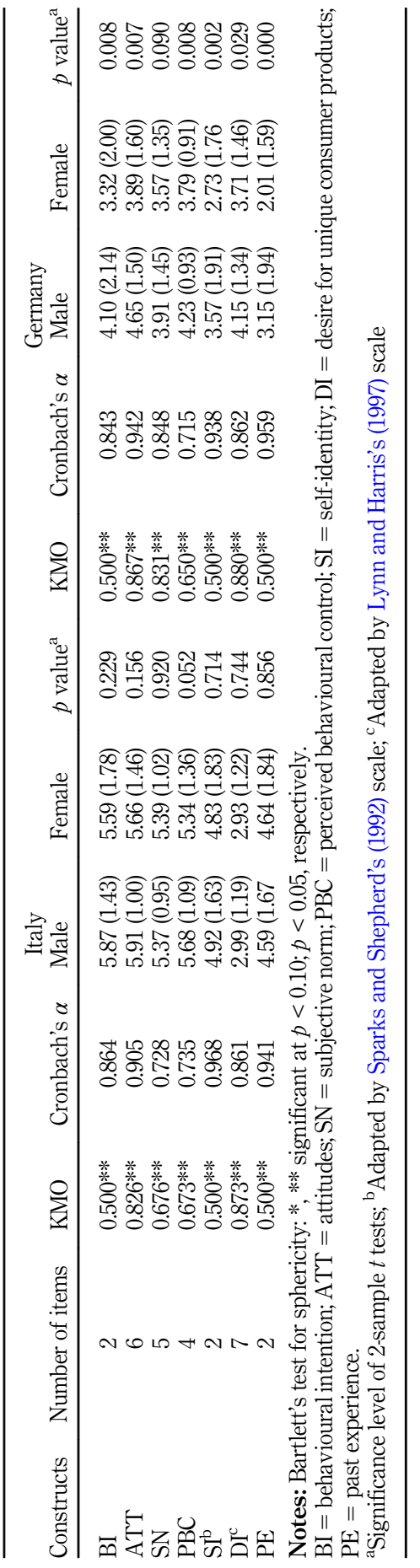

Table II.

Constructs and descriptive statistics (Mean, standard deviation in parenthesis) 
towards $\mathrm{CB}$ consumption (subjective norm $(\mathrm{SN})$ ), individual perception of being able to control the consumption of $\mathrm{CB}$ (perceived behavioural control (PBC)), self-identity (SI) as a "real" craft consumer, desire for unique consumer products (DI), and CB-drinking experiences (past experience (PE)) as the independent variables.

Gender effects were tested using a moderation approach, with simultaneous interaction terms between gender (male as the reference category) and each independent variable. Gender was also considered as an independent variable. Multicollinearity was investigated by inspecting the variance inflation factors (VIFs), which examine the possibility that one construct is a linear function of the other (Kutner et al., 2004). The VIFs for the predictors in the Italian sample ranged from 1.77 to 3.38 with a mean of 2.24 (Table III), whereas for the German sample, the VIFs ranged from 1.46 to 3.32 with a mean of 2.68; therefore, the values of the sample are below the commonly considered cut-off value that signals potential multicollinearity issues (Hair et al., 1998).

\section{Results}

\subsection{Descriptive statistics}

Table II shows the descriptive statistics of the samples. Italian males showed a significantly stronger belief of being able to control their $\mathrm{CB}$ consumption (mean value $=5.68$; standard deviation $[\mathrm{SD}]=1.09 ; p=0.052$ ) than females (mean value $=5.34 ; \mathrm{SD}=1.36$ ). In contrast, the mean values of all the other constructs were not significantly different between Italian male and female participants. However, considerable gender differences were found in the German sample for all constructs, with higher mean values for male respondents.

\subsection{Moderated regression analysis}

Table III depicts the results of the moderated regression analysis. For the Italian sample, the F-test $(F(13,186)=33.01, p<0.000)$ indicated a good model fit of the regression model. In addition, the validated model explained well more than 67 per cent of the variance in the respondents' intention to consume $\mathrm{CB}$. ATT towards $\mathrm{CB}$ predicted the intention to consume CB for both men (ATT: $\beta=0.190, p=0.007$ ) and women (ATT: $\beta=0.205, p=0.000$ ), without

\begin{tabular}{lcccccccc}
\hline & \multicolumn{4}{c}{ Italy } \\
Regression analysis & Coef. & S.E. & $p>|t|$ & $\mathrm{VIF}^{\mathrm{a}}$ & Coef. & S.E. & $p>|t|$ & $\mathrm{VIF}^{\mathrm{a}}$ \\
\hline ATT male & 0.190 & 0.068 & $0.007^{* *}$ & 2.23 & 0.299 & 0.072 & $0.000^{* * *}$ & 3.23 \\
ATT female $\times$ male & 0.015 & 0.086 & 0.864 & - & -0.141 & 0.090 & 0.119 & - \\
SN male & 0.106 & 0.067 & 0.115 & 1.77 & 0.140 & 0.078 & $0.075^{*}$ & 2.98 \\
SN female $\times$ male & -0.034 & 0.092 & 0.714 & - & 0.002 & 0.105 & 0.987 & - \\
PBC male & 0.264 & 0.089 & $0.004^{* *}$ & 2.13 & 0.087 & 0.065 & 0.183 & 1.46 \\
PBC female $\times$ male & -0.194 & 0.111 & $0.083^{*}$ & - & -0.085 & 0.086 & 0.323 & - \\
SI male & 0.012 & 0.099 & 0.900 & 3.38 & 0.076 & 0.110 & 0.490 & 3.32 \\
SI female $\times$ male & 0.455 & 0.142 & $0.002^{* *}$ & - & 0.220 & 0.143 & 0.125 & - \\
DI male & 0.012 & 0.060 & 0.849 & 1.85 & 0.040 & 0.068 & 0.556 & 2.24 \\
DI female $\times$ male & -0.010 & 0.078 & 0.895 & - & -0.047 & 0.083 & 0.576 & \\
PE male & 0.219 & 0.090 & $0.017^{* *}$ & 2.08 & 0.066 & 0.091 & 0.472 & 2.84 \\
PE female $\times$ male & -0.222 & 0.118 & $0.061^{*}$ & - & 0.136 & 0.134 & 0.310 & - \\
Constant male & 0.032 & 0.076 & 0.672 & - & -0.021 & 0.082 & 0.795 & - \\
Constant female $\times$ male & -0.075 & 0.109 & 0.491 & - & 0.062 & 0.112 & 0.578 & -
\end{tabular}

Notes: *, **significant at $p<0.10 ; p<0.05$.

Dependent variable: $\mathrm{BI}=$ behavioural intention; $\mathrm{ATT}=$ attitudes; $\mathrm{SN}=$ subjective norm; $\mathrm{PBC}=$ perceived behavioural control; SI = self-identity; DI = desire for unique consumer products; $\mathrm{PE}=$ past experience.

aIF: variable inflation factor referred to the whole sample.

The difference of female's coefficients compared to male's coefficients is in italics. Gender (male as reference)
Is craft beer consumption genderless?

935 
$\mathrm{BFJ}$

122,3

936 a significant gender difference. Social pressure and the desire for unique consumer products were not significantly predictive for either men (SN: $\beta=0.106, p=0.115$; DI: $\beta=0.012$, $p=0.849$ ) or women (SN: $\beta=0.072, p=0.248 ; \mathrm{DI}: \beta=0.001, p=0.981$ ) and were also without significant gender differences.

Significant moderation effects of gender in the Italian sample were found for three drivers of $\mathrm{CB}$ consumption: $\mathrm{PBC} \times$ Gender $(\beta=-0.194, p=0.083)$, $\mathrm{SI} \times \operatorname{Gender}(\beta=0.455, p=0.002)$ and $\mathrm{PE} \times \operatorname{Gender}(\beta=-0.222, p=0.061)$. These moderation effects revealed that perceived behavioural control and consumption experience (social influence) have (has) a stronger effect on males' (females') inclination towards CB consumption. In line with the uncovered moderation effects, the belief of men of being able to control their consumption of $\mathrm{CB}$ (i.e., PBC: $\beta=0.264, p=0.004$ ) and their self-perception as experienced $\mathrm{CB}$ drinkers (i.e., PE: $\beta=0.219, p=0.017$ ) were two relevant drivers of the intention to consume CBs among males. However, self-identification as CB consumers did not affect men's intention to purchase and consume CB (SI: $\beta=0.012, p=0.900$ ) but was a significant behavioural driver for women (SI: $\beta=0.468, p=0.000$ ). In addition, a supplementary mediation analysis with multiple independent variables and attitude as a mediator, which was conducted with Hayes' (2012) MEDIATE macro, revealed a significant indirect effect of SI on behavioural intention $(\beta=0.130$, lower limit confidence interval $(\mathrm{LLCI})(95$ per cent $)=0.057$, upper limit confidence interval (ULCI) $(95$ per cent) $=284$ ) for all Italian respondents.

The regression results for the German sample (Table III) revealed the predictive power of the validated model $(F(13,186)=34.7, p<0.000)$, which accounted for more than 68 per cent of BI's observed variance. Both ATTs towards CB (ATT: $\beta=0.299, p=0.000$ ) and social norms (SN: $\beta=0.140, p=0.063$ ) were significantly associated with the German male respondents' intention to consume $\mathrm{CB}(\mathrm{BI})$. Again, a mediation analysis with multiple independent variables and attitude as a mediator with Hayes' (2012) MEDIATE macro was conducted. The mediation analysis revealed significant and positive indirect effects of PE $(\beta=0.040$, LLCI $(95$ per cent $)=0.002$, ULCI $(95$ per cent $)=0.091)$ and DI $(\beta=0.062, \operatorname{LLCI}(95$ per cent $)=0.028$, ULCI $(95$ per cent $)=0.106)$. As shown in Table III, the regression approach revealed no significant moderation effects of gender; hence, the drivers of the inclination of $\mathrm{CB}$ consumption do not differ among German males and females.

\section{Discussion}

Prior investigations have documented the reconfigured role of gender in beer consumption, highlighting how consumption patterns are changing; Darwin, for example, reports that beer has become a totem of femininity through the consumption of CB (Darwin, 2017). The findings of our investigation provide an initial picture of gender-specific $\mathrm{CB}$ consumption patterns in Italy and Germany, two European countries characterised by different beer cultures. To assess whether $\mathrm{CB}$ consumption behaviour represents an example of gender convergence (or difference) in beer consumption, we conducted a moderated regression analysis with gender as a moderator.

In line with the findings of Gómez-Corona et al. (2016a), we identified gender differences in attitudes towards $\mathrm{CB}$ consumption both in the Italian and German samples. This finding is in line with the predictions of the gender socialisation theory, among others. However, these gender differences are only moderate. On the other hand, and in particular in the Italian sample, the findings of the present study point in the direction of the findings of Darwin's study that shows that women do not exhibit any frustration with being considered CB drinkers and suggests that $\mathrm{CB}$ consumption is genderless. In addition to other theoretical explanations, this finding may be the result of greater gender equality in the countries considered.

This study's finding reveals that the individual self-identification as a CB drinker has no strong direct effect on the intention to consume $\mathrm{CB}$ and that no gender differences exist in this 
regard. In particular, Italian women are as inclined as Italian men to consider themselves as typical CB drinkers (Table II). In line with the theory of multidimensional gender identities, these findings support those of Chapman et al., confirming that 'to be a real craft beer drinker and a woman are not two mutually exclusive categories' (Chapman et al., 2018: 306). Genderspecific differences in consumer identities have disappeared, or multidimensional identities have blurred the effect of the binary gender variable in the $\mathrm{CB}$ domain in this regard.

In the Italian sample, we found that men's intention to consume $\mathrm{CB}$ was more strongly associated with PBC and with PE than that of women. These findings support Darwin's considerations, according to which men tend to legitimate the consumption of any beer by invoking their ability to take a risk in alcohol consumption and their experience as beer drinkers (Darwin, 2018). This finding reflects a typical male consumer identity, which is probably not limited to the consumption of $\mathrm{CB}$ but is valid for all alcoholic beverages. For Italian males and conforming to the anthropological evolutionary theory, drinking $\mathrm{CB}$ appears to be a showy consumer behaviour through which self-images can be enhanced. Furthermore, this result is in agreement with Chapman's notion, which states that gender is actively renegotiated and accomplished through CB consumption (Chapman et al., 2018); in particular, Italian men seem to renegotiate their role as 'real' men who have everything under control in the realm of $\mathrm{CB}$ consumption, which is a consumption arena in which the gender hierarchy is progressively losing its power. The significant and positive gender $\times$ SI moderation effect in the Italian subsample can be regarded as an indication of the ongoing process of gender convergence in the $\mathrm{CB}$ domain. In sum, the contrary moderation effects of gender may be the reason for the consistent behavioural intentions in Italian men and women.

When looking at the German sample and in contrast to the Italian sample, no significant moderation effects of gender were found. This result could be understood as the absence of gender barriers within the realm of $\mathrm{CB}$ consumption in Germany; that is to say, $\mathrm{CB}$ consumption is genderless. These insights also echo the argument of Holmila and Ratislao, who have raised the question of the convergence of male and female drinking (Holmila and Raitasalo, 2005). However, the descriptive statistics show distinct gender-specific differences in the mean value of all considered constructs. Here, the lower mean values of BI and ATT indicate that German females are less inclined towards CB than are German males. This result is in line with the anthropological evolutionary theory, which predicts that males are more inclined towards risky or adventurous behaviour such as alcohol consumption. Interestingly, women's willingness to pay for CB contradicts these findings (Table II). Women may be willing to pay more for $\mathrm{CB}$ either because they assume a positive price-product quality relationship when making their purchasing decisions or they plan to consume less $\mathrm{CB}$ and thus believe in having a higher per-item budget. Furthermore, the significant mean value difference that appeared for the $\mathrm{PBC}$ construct is in line with the moderated regression findings in the Italian sample. In addition, the significant mean difference in SI indicates that there is still a gender-specific identity difference in the CB domain. In summary, one can state that there are, to a certain extent, gender differences in $\mathrm{CB}$ consumption in Germany. The mean differences in gender indicate a steady and still masculine value system regarding beer consumption. The absent moderation effect of gender shows that gender-specific attitudes and beliefs are stable and rather invariable in Germany. Against the background of the centuries-old beer culture in Germany, these findings have face validity.

\section{Conclusions}

To the best of our knowledge, this research is the first comparative study that investigates the gender differences in $\mathrm{CB}$ consumption in Europe. This research fills a gap in the literature by exploring whether $\mathrm{CB}$ consumption in Italy and Germany is genderless. The findings indicate that in a consumption sphere strongly associated with masculinity, such as beer
Is craft beer consumption genderless? 
$\mathrm{BFJ}$

122,3

938 consumption, new consumption patterns in which femininity is not undermined per se are possible.

These findings can help industry managers to create appropriate marketing strategies to better capture gender-specific preferences in $\mathrm{CB}$ consumption. In particular, the $\mathrm{CB}$ segment could be an entry point for women into the typically male-dominated beer market. Marketing managers could try to specifically target women who already consume $\mathrm{CB}$ and get them excited about other products from their product portfolio. This strategy could alleviate the decreases in overall beer sales. In Italy, marketing managers could promote a feminine product image of $\mathrm{CB}$ by different means of communication, such as print advertisements or social media campaigns. The resulting higher SI should boost females' intention to buy CB. Advertisements that are seen by Italian men should encourage the men in their CB expertise and experience, and this should get more men to buy $\mathrm{CB}$. Because the drivers of $\mathrm{CB}$ consumption in the validated model did not differ across the two genders for the German respondents, a gender-specific segmentation strategy does not appear effective in Germany. Instead, marketing managers could use celebrity and noncelebrity endorsements to increase the social pressure to consume $\mathrm{CB}$ that appears to be a distinct driver of $\mathrm{CB}$ consumption. In addition, a similar effect could be achieved using social marketing that aims to boost electronic word of mouth (eWOM) behaviour.

The study results should be interpreted against the background of the existing study limitations. One of the limitations of our data is the small sample sizes that might result in the limited validity of the study findings. Thus, further large-scale quantitative replication studies could undoubtedly strengthen the findings. Furthermore, the present study solely focuses on two European countries, and thus, the external validity might be limited. However, the research design explicitly considers two countries with distinctly different beer cultures, and this approach should have increased the generalisability of our findings. Finally, the validated model considers behavioural intentions as the dependent variable and intentions never correctly translate into actual behaviour. Hence, and based on market data from $\mathrm{CB}$ manufacturers, future research should try to explain actual CB purchasing behaviour based on the considered behavioural model.

Moreover, the present study findings provide avenues for future research; the findings of this study expand the knowledge on the gendered nature of $\mathrm{CB}$ consumption and bring forward valuable insights into the consumption of crafted food products. Our results are encouraging and should be validated in specific age cohorts that are relevant for the $\mathrm{CB}$ sector (e.g., millennials), as well as in other countries, to shed light on the gender differences in $\mathrm{CB}$ consumption. In our study, we found substantial differences between the $\mathrm{CB}$ consumption patterns of Italians and Germans. Such findings support those that have demonstrated that drinking behaviour is also related to the culture of different societies (Baraona et al., 2001; Gómez-Corona et al., 2017a). For example, even though Italians and Germans both express positive attitudes towards $\mathrm{CB}$, the perceived social pressure (i.e., social norms) has a significant positive effect on the intention to consume $\mathrm{CB}$ for only the German sample. The long-term tradition of beer production and consumption has probably made this aspect relevant to the decision-making process of German consumers. Instead, previous $\mathrm{CB}$ drinking experiences and the conviction of being able to control the consumption of $\mathrm{CB}$ appeared as two fundamental motives that are relevant for the explanation of Italians' intention to consume CB. Thus, future studies can address these cultural differences in $\mathrm{CB}$ consumption more deeply. For example, the culturally diverse United States, with their long history of migration from different parts of the world, could be a fruitful research object. Moreover, studies that elaborate on different consumption patterns across various subcultures (e.g., urban vs rural beer cultures) could result in fruitful insights. Finally, as the study is based on questionnaire data, it must be noted that the study results are, to some extent, descriptiveand one cannot make statements regarding causal dependencies. Accordingly, future study on $\mathrm{CB}$ consumption should increasingly consider experimental research design. 


\section{References}

Ajzen, I. (1991), "The theory of planned behavior", Organizational Behavior and Human Decision Processes, Vol. 50 No. 1, pp. 179-211.

Aquilani, B., Laureti, T., Poponi, S. and Secondi, L. (2015), "Beer choice and consumption determinants when craft beers are tasted: an exploratory study of consumer preferences", Food Quality and Preference, Vol. 41, pp. 214-224.

Baraona, E., Abittan, C.S., Dohmen, K., Moretti, M., Pozzato, G., Chayes, Z.W., Schaefer, C. and Lieber, C.S. (2001), "Gender differences in pharmacokinetics of alcohol", Alcoholism: Clinical and Experimental Research, Vol. 25 No. 4, pp. 502-507.

Beardsworth, A., Bryman, A., Keil, T., Goode, J., Haslam, C. and Lancashire, E. (2002), "Women, men and food: the significance of gender for nutritional attitudes and choices", British Food Journal, Vol. 104 No. 7, pp. 470-491.

Betz, M., O'Connell, L. and Shepard, J.M. (1989), "Gender differences in proclivity for unethical behavior", Citation Classics from The Journal of Business Ethics: Celebrating the First Thirty Years of Publication, pp. 427-432.

Chapman, N.G., Nanney, M., Slade Lellock, J. and Mikles-Schluterman, J. (2018), "Bottling gender: accomplishing gender through craft beer consumption”, Food, Culture and Society, Vol. 21 No. 3, pp. 296-313.

Chodorow, N. (1978), The Reproduction of Mothering: Psychoanalysis and the Sociology of Gender, University of California Press, Los Angeles.

Clarke, J. (2012), “Who is the new beer consumer?”, available at: https://www.beveragemedia.com/2012/ 05/01/who-is-the-new-beer-consumer-brewers-ready-to-say-ihola-and-more-to-expand-reach/ (accessed 6 June 2019).

Cooper, P.J., Pauletti, R.E., Tobin, D.D., Menon, M., Menon, M., Spatta, B.C., Hodges, E.V.E. and Perry, D.G. (2013), "Mother-child attachment and gender identity in preadolescence", Sex Roles, Vol. 69 No. 11-12, pp. 618-631.

Darwin, H. (2017), "You are what you drink: gender stereotypes and craft beer preferences within the craft beer scene of New York city", in Chapman, N.G., Lellock, J.S., Lippard, C.D. (Eds), Untapped: Exploring the Cultural Dimensions of Craft Beer, West Virginia University Press, Morgantown. WV, pp. 222-235.

Darwin, H. (2018), "Omnivorous masculinity: gender capital and cultural legitimacy in craft beer culture”, Social Currents, Vol. 5 No. 3, pp. 301-316.

Dawson, L.M. (1997), “Ethical differences between men and women in the sales profession”, Journal of Business Ethics, Vol. 16 No. 11, pp. 1143-1152.

Dempster, S. (2011), "I drink, therefore I'm man: gender discourses, alcohol and the construction of British undergraduate masculinities", Gender and Education, Vol. 23 No. 5, pp. 635-653.

Donadini, G., Fumi, M.D., Kordialik-Bogacka, E., Maggi, L., Lambri, M. and Sckokai, P. (2016), "Consumer interest in specialty beers in three European markets", Food Research International, Vol. 85, pp. 301-314.

Donadini, G. and Porretta, S. (2017), "Uncovering patterns of consumers' interest for beer: a case study with craft beers”, Food Research International, Elsevier Ltd, Vol. 91, pp. 183-198.

Fernie, G., Cole, J.C., Goudie, A.J. and Field, M. (2010), "Risk-taking but not response inhibition or delay discounting predict alcohol consumption in social drinkers", Drug and Alcohol Dependence, Elsevier Ireland Ltd, Vol. 112 No. 1-2, pp. 54-61.

Freud, S. (1925), “Negation”, International Journal of Psycho-Analysis, Vol. 6, pp. 367-371.

Fugitt, J.L. and Ham, L.S. (2018), "Beer for 'brohood': a laboratory simulation of masculinity confirmation through alcohol use behaviors in men”, Psychology of Addictive Behaviors, Vol. 32 No. 3, pp. 358-364. 
$\mathrm{BFJ}$ 122,3

\section{0}

Garavaglia, C. and Swinnen, J. (2018), Economic Perspectives on Craft Beers - A Revolution in the Global Beer Industry, Springer International Publishing, Palgrave Macmillan, Switzerland, available at: https://doi.org/10.1007/978-3-319-58235-1.

Gómez-Corona, C., Escalona-Buendía, H.B., García, M., Chollet, S. and Valentin, D. (2016a), "Craft vs industrial: Habits, attitudes and motivations towards beer consumption in Mexico", Appetite, Vol. 96, pp. 358-367.

Gómez-Corona, C., Lelievre-Desmas, M., Escalona Buendía, H.B., Chollet, S. and Valentin, D. (2016b), "Craft beer representation amongst men in two different cultures", Food Quality and Preference, Vol. 53, pp. 19-28.

Gómez-Corona, C., Valentin, D., Escalona-Buendía, H.B. and Chollet, S. (2017a), "The role of gender and product consumption in the mental representation of industrial and craft beers: an exploratory study with Mexican consumers", Food Quality and Preference, Elsevier, Vol. 60 No. February, pp. 31-39.

Gómez-Corona, C., Escalona-Buendía, H.B., Chollet, S. and Valentin, D. (2017b), "The building blocks of drinking experience across men and women: a case study with craft and industrial beers", Appetite, Vol. 116, pp. 345-356.

Gorka, S.M., Liu, H., Klein, D., Daughters, S.B. and Shankman, S.A. (2015), "Is risk-taking propensity a familial vulnerability factor for alcohol use? An examination in two independent samples", Journal of Psychiatric Research, Elsevier Ltd, Vol. 68, pp. 54-60.

Graham, K., Wilsnack, R., Dawson, D. and Vogeltanz, N. (1998), "Should alcohol consumption measures be adjusted for gender differences?”, Addiction, Vol. 93 No. 8, pp. 1137-1147.

Hair, J.F., Anderson, R.E., Tatham, R.L. and Black, W.C. (1998), Multivariate Data Analysis, 5th ed., Prentice Hall, Upper Saddle River, N.J.

Hayes, A.F. (2012), "My macros and code for SPSS and SAS", available at: http://afhayes.com/spsssas-and-mplus-macros-and-code.html (accessed 21 October 2019).

Holmila, M. and Raitasalo, K. (2005), "Gender differences in drinking: why do they still exist?", Addiction, Vol. 100 No. 12, pp. 1763-1769.

Kerr, W.C., Greenfield, T.K., Bond, J., Ye, Y. and Rehm, J. (2004), “Age, period and cohort influences on beer, wine and spirits consumption trends in the US National Alcohol Surveys", Addiction, Vol. 99 No. 9, pp. 1111-1120.

Kurt, D. and Frimer, J. (2015), "Agency and communion as a framework to understand consumer behavior", in Norton, M.I., Rucker, D.D. and Lamberton, C. (Eds), The Cambridge Handbook of Consumer Psychology, Cambridge University Press, Cambridge, MA, pp. 446-475.

Kutner, N.H., Nachtsheim, C. and Neter, J. (2004), Applied Linear Regression Models, McGraw-Hill/ Irwin, Boston, MA, USA, New York, NY, USA.

Lieber, C.S. (2006), "Ethnic and gender differences in ethanol metabolism", Alcoholism: Clinical and Experimental Research, Vol. 24 No. 4, pp. 417-418.

Liebman, M., Propst, K., Moore, S.A., Pelican, S., Holmes, B., Wardlaw, M.K., Melcher, L.M., Harker, J.C., Dennee, P.M. and Dunnagan, T. (2003), "Gender differences in selected dietary intakes and eating behaviors in rural communities in Wyoming, Montana, and Idaho", Nutrition Research, Vol. 23 No. 8, pp. 991-1002.

Lynn, M. and Harris, J. (1997), "The desire for unique consumer products: a new individual differences scale", Psychology and Marketing, Vol. 14 No. 6, pp. 601-616.

Mead, A.S. (2009), "Gender differences in food selections of students at a historically black college and university (HBCU)", College Student Journal, Vol. 43 No. 3, pp. 800-806.

Medina-mora, E. (1994), "Drinking and the oppression of women: the Mexican experience", Addiction, Vol. 89 No. 8, pp. 958-960.

Mejlholm, O. and Martens, M. (2006), "Beer identity in Denmark", Food Quality and Preference, Vol. 17 No. 1-2, pp. 108-115. 
Menon, M. (2017), "Multidimensional gender identity and gender-typed relationship styles in adolescence", Sex Roles, Vol. 76 No. 9-10, pp. 579-591.

Meyers-Levy, J. and Loken, B. (2015), "Revisiting gender differences: what we know and what lies ahead", Journal of Consumer Psychology, Vol. 25 No. 1, pp. 129-149.

Mora, M., Urdaneta, E. and Chaya, C. (2018), "Emotional response to wine: sensory properties, age and gender as drivers of consumers' preferences", Food Quality and Preference, Elsevier, Vol. 66 No. July 2017, pp. 19-28.

Muggah, E.M. and McSweeney, M.B. (2017), "Using preferred attribute elicitation to determine how males and females evaluate beer", Journal of Food Science, Vol. 82 No. 8, pp. 1916-1923.

Newman, K.P. and Trump, R.K. (2019), "Reducing skepticism about corporate social responsibility: roles of gender and agentic-communal orientations", Journal of Consumer Marketing, Vol. 36 No. 1, pp. 189-196.

Rivaroli, S., Hingley, M.K. and Spadoni, R. (2018), "The motivation behind drinking craft beer in Italian brew pubs: a case study”, Economia Agro-Alimentare, Vol. 20 No. 3, pp. 425-443.

Rivaroli, S., Lindenmeier, J. and Spadoni, R. (2019), "Attitudes and motivations toward craft beer consumption: an explanatory study in two different countries", Journal of Food Products Marketing, Routledge, Vol. 25 No. 3, pp. 276-294.

Roberts, B. (2004), "Drinking like a man: the paradox of excessive drinking for seventeenth-century Dutch youths", Journal of Family History, Vol. 29 No. 3, pp. 237-252.

Roxas, M.L. and Stoneback, J.Y. (2004), "The importance of gender across cultures in ethical decisionmaking”, Journal of Business Ethics, Vol. 50 No. 2, pp. 149-165.

Ruhl, H., Dolan, E.A. and Buhrmester, D. (2015), "Adolescent attachment trajectories with mothers and fathers: the importance of parent-child relationship experiences and gender", Journal of Research on Adolescence, Vol. 25 No. 3, pp. 427-442.

Slentz, K.L. and Krogh, S.L. (2017), Early Childhood Development and its Variations, Routledge, New York, NY, available at: https://doi.org/10.4324/9781351225588.

Snider, M. (2016), "Women to get their own beer; will they want it?", available at: https://eu.usatoday. com/story/money/2016/05/21/women-get-but-they-want-their-own-beer/83857942/ (accessed 6 June 2019).

Sparks, P. and Shepherd, R. (1992), "Self-identity and the theory of planned behavior: assesing the role of identification with "green consumerism"”, Social Psychology Quarterly, American Sociological Association, Vol. 55 No. 4, pp. 388-399.

Spence, J.T. (1993), "Gender-related traits and gender ideology: evidence for a multifactorial theory", Journal of Personality and Social Psychology, Vol. 64 No. 4, pp. 624-635.

Statista GmbH (2017), Craft Beer, Statista, Hamburg (Germany).

The World Bank (2017), Population, Female (\% of Total), available at: https://data.worldbank.org/ indicator/SP.POP.TOTL.FE.ZS? contextual $=$ default\&end $=2017 \&$ locations $=$ IT-DE-1W\&name desc $=$ false \&start $=2011 \&$ view $=$ chart $($ accessed 22 May 2019).

Thompson, C.J. and Holt, D.B. (2004), "How do men grab the phallus? Gender tourism in everyday consumption”, Journal of Consumer Culture, Vol. 4 No. 3, pp. 313-338.

de Visser, R.O. and McDonnell, E.J. (2012), “That's OK. He's a guy': a mixed-methods study of gender double-standards for alcohol use", Psychology and Health, Vol. 27 No. 5, pp. 618-639.

Weeks, W.A., Moore, C.W., McKinney, J.A. and Longenecker, J.G. (1999), "The effects of gender and career stage on ethical judgment”, Journal of Business Ethics, Vol. 20 No. 4, pp. 301-313.

Wilsnack, R.W., Wilsnack, S.C., Kristjanson, A.F., Vogeltanz-Holm, N.D. and Gmel, G. (2009), "Gender and alcohol consumption: patterns from the multinational GENACIS project", Addiction, Vol. 104 No. 9, pp. 1487-1500.
Is craft beer consumption genderless? 
BFJ

122,3

\section{Appendix}

\section{Measures}

Behavioural intention (BI)

(1) * Will you consume craft beer soon? $(1=$ Certainly / $71=$ Definitely not);

942

(2) Will you consume craft beer soon? $(1=$ I do not want to consume craft beer / 7 = I want to consume craft beer).

Attitude (ATT)

(1) * For me to drink craft beer is $1=$ Tasty / 7 = Disgusting;

(2) * For me to drink craft beer is $1=$ Useful / 7 = Useless;

(3) For me to drink craft beer is $1=$ Negative $/ 7$ = Positive;

(4) $*$ For me to drink craft beer is $1=$ Healthy $/ 7=$ Unhealthy;

(5) $*$ For me to drink craft beer is $1=$ Intelligent / $7=$ Foolish;

(6) For me to drink craft beer is $1=$ Unpleasant $/ 7=$ Pleasant.

Subjective norm (SN)

(1) Think about people that are important for you: How many of them drink craft beer? $(1=$ No one $/ 7$ = All);

(2) * How probable is that they would drink craft beer? $(1=$ Highly probable $/ 7=$ Improbable);

(3) How many of them could drink craft beer? $(1=0$ per cent / $7=100$ per cent);

(4) * Do they approve or disapprove the consumption of craft beer? $(1=$ Approve / 7 = Disapprove);

(5) How many think that drinking craft beer is a good alternative to the consumption of other beers? $(1=$ No one $/ 7=$ All $)$.

Perceived behavioural control (PBC)

(1) * It is simple/easy for me to consume craft beer. ( $1=$ Agree $/ 7=$ Disagree);

(2) * I can completely control my consumption of craft beer. $(1=$ Agree $/ 7=$ Disagree);

(3) I feel able to control the consumption of craft beer. $(1=$ Totally false, $7=$ Totally true);

(4) * In the next future, consuming craft beer will be for me: $1=$ Likely / $7=$ Impossible.

Self-identity (SI)

(1) I consider myself as a typical craft beer consumer ( 1 = Strongly agree, 7 = Strongly disagree);

(2) In the future, I could consider myself as a typical craft beer consumer (1 = Agree very strongly, $7=$ Disagree very strongly).

Desire for unique consumer products (DI)

(1) I am very attracted by special beers ( $1=$ Completely agree, $7=$ Completely disagree);

(2) I have the tendency to be nonconformist rather than following the trends of the moment ( 1 = Completely agree, $7=$ Completely disagree);

(3) * I have the tendency to buy products that are hard to be found ( $1=$ Completely agree, 7 = Completely disagree);

(4) * I prefer to use personalised products rather than standard ones $(1=$ Completely agree, 7 = Completely disagree); 
(5) * I rarely miss the opportunity to personalise things that I'm buying $(1=$ Completely agree, 7 = Completely disagree);

(6) * I like to try new products and services before others $(1=$ Completely agree, $7=$ Completely disagree);

(7) * I like to buy in shops that sell different and uncommon products $(1=$ Completely agree, 7 = Completely disagree).

Past experience (PE)

Is craft beer consumption genderless?

(1) How often have you consumed craft beer within the last six months $(1=$ Never, $7=$ Usually);

(2) How often have you consumed craft beer within the last year ( $1=$ Never, $7=$ Usually).

Notes: * Reverse-scaled

\begin{abstract}
About the authors
Sergio Rivaroli, who has a $\mathrm{PhD}$ in agricultural economics and policy, at present is an adjunct professor at the University of Bologna, Department of Agricultural and Food Sciences, Italy. His research focuses on consumer economics, food economics, and prosocial behaviour. Sergio Rivaroli is the corresponding author and can be contacted at: sergio.rivaroli@unibo.it

Jörg Lindenmeier is a full professor of public and nonprofit management at the University of Freiburg, Germany. His research focuses on consumer and prosocial behaviour as well as on business ethics and corporate social responsibility.

Roberta Spadoni, who has a $\mathrm{PhD}$ in economics of the agrifood systems, at present is an associate professor at the University of Bologna, Department of Agricultural and Food Sciences, Italy. Main fields of interest are economics of agricultural and food markets, certification systems, agricultural and industrial marketing and product quality issues.
\end{abstract}

For instructions on how to order reprints of this article, please visit our website: 